\title{
Mothers' human papilloma virus knowledge and willingness to vaccinate their adolescent daughters in Lagos, Nigeria
}

This article was published in the following Dove Press journal:

International Journal of Women's Health

3 July 2013

Number of times this article has been viewed

\author{
Beatrice N Ezenwa' \\ Mobolanle R Balogun ${ }^{2}$ \\ Ifeoma P Okafor ${ }^{2}$ \\ 'Department of Pediatrics, \\ 68 Nigerian Army Reference Hospital, \\ Lagos State, Nigeria; ${ }^{2}$ Department \\ of Community Health and Primary \\ Care, College of Medicine, University \\ of Lagos, Lagos State, Nigeria
}

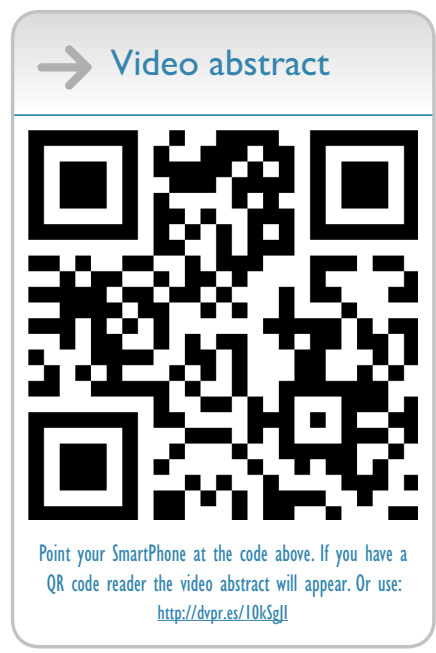

Correspondence: Beatrice Ezenwa Department of Pediatrics, 68 Nigerian Army Reference Hospital, PMB 2004,

Yaba, Lagos State, Nigeria

Tel +234805 I40 3I89

Email beatriceezenwa@yahoo.com
Introduction: Human papillomavirus (HPV) is one of the most common sexually transmitted infections in sexually active adolescents and young women and has been implicated as a cause of the majority of cases of cervical cancer, which is the second most common cancer in women in Nigeria. HPV is preventable with the use of HPV vaccines.

Objectives: The objective of this study was to assess mothers' HPV knowledge and their willingness to vaccinate their adolescent daughters in Lagos, Nigeria.

Materials and methods: This study was a community-based, descriptive cross-sectional study carried out in July, 2012 in Shomolu Local Government Area (LGA) of Lagos State, Nigeria. Multistage sampling method was employed to select the 290 respondents who participated in the study. Structured, pretested, interviewer-administered questionnaires were used for data collection. Data was analyzed with Epi Info ${ }^{\mathrm{TM}}$ version 7.

Results: The study revealed low awareness of HPV (27.9\%) and HPV vaccines $(19.7 \%)$ among the mothers that participated. There was a high awareness for cervical cancer but little knowledge of its link to HPV. Awareness and utilization of HPV vaccines increased with increasing educational level $(P<0.05)$. There was a high willingness and intention among the mothers to vaccinate their girls $(88.9 \%)$ and to recommend the vaccine to others $(91.0 \%)$. Accessibility and affordability of the HPV vaccines were found to be possible barriers to future utilization of the vaccines.

Conclusion: Despite low knowledge about HPV and HPV vaccines, mothers were willing to vaccinate their daughters. We recommend improving mothers' knowledge by education and the possible inclusion of the vaccine in the national immunization schedule to eliminate the financial barrier.

Keywords: HPV, vaccine, Nigeria

\section{Background}

Human papillomavirus (HPV) is one of the most common sexually transmitted infections in sexually active adolescents and young women, ${ }^{1,2}$ although HPV can occur in women of all age groups. ${ }^{1,3}$ Though the incidence of HPV infection is not precisely known, yet it is estimated that globally $75 \%$ of individuals (males and females) will experience an HPV infection at least once in their lifetime, with the highest rates of infection occurring in individuals under the age of $25 .{ }^{4}$ Over $50 \%$ of sexually active women are exposed to at least one HPV type during their lifetime. ${ }^{2}$ In a meta-analysis conducted by researchers in Spain, a global HPV prevalence of $11.7 \%$ was reported. The HPV prevalence in North America and Europe was estimated at 11.5\% and 14.2\%, respectively while the prevalence in Africa was estimated at $21.1 \%$ with sub-Saharan Africa topping the list at $24 \%{ }^{3,5}$ The high prevalence of HPV in sub-Saharan Africa 
was attributed to impairment in cellular immunity as a result of chronic cervical inflammation, parasitic infection, micronutrient deficiency, and HIV, which are very prevalent in this region. ${ }^{6}$ In Nigeria, HPV prevalence is high across all female ages but it is highest among 15-23 year olds. ${ }^{7}$

There are over 100 different viral genotypes of HPV; ${ }^{8}$ some affect the genitals, while others affect the oropharynx and skin. Most genital infections are asymptomatic, transient, and resolve spontaneously without any invasive disease. ${ }^{9}$ Persistence of infection with HPV high risk types 16 and 18 is responsible for the etiology of cervical cancer in approximately $70 \%$ of cases of cervical cancer. ${ }^{2}$

Cervical cancer is the second most common cancer in women worldwide and the second most common cancer in women aged 15-44 years in Nigeria. ${ }^{2,7,10}$ Half a million women develop cervical cancer annually and more than half of these individuals die from the disease. ${ }^{2}$ In 2008, more than 270,000 women died of cervical cancer worldwide, nearly $85 \%$ of them in developing countries. ${ }^{7,10}$ Each year, $6 \%$ of the nine million new cases of all cancers worldwide and $20 \%$ to $24 \%$ of all cancers in women in Latin America, South-west Asia, and sub-Saharan Africa are attributable to HPV infection. ${ }^{11}$ The incidence rate of cervical cancer in Nigeria is 25/100,000 while the reported prevalence rate for HPV in the general population is $26.3 \% .^{7,10}$ The incidence of HPV in women with cervical cancer is reported to be $24.8 \%{ }^{10,11}$ Most cases of cancer of the cervix, especially in developing countries, present at advanced stages when curative measures are unlikely to be successful. ${ }^{10}$

Fortunately, HPV is preventable with the use of HPV vaccines. HPV vaccines are prepared from empty protein shells called virus-like particles (VLP) produced using recombinant technology ${ }^{12,13}$ and they are designed to be prophylactic (ie, to prevent infection and consequent disease). ${ }^{14}$ Early studies with a monovalent vaccine against HPV 16 have shown that VLP vaccines induce a strong immune response in animal models ${ }^{15,16}$ and humoral immunity in humans. ${ }^{17}$ Immune responses to HPV infection are typespecific; therefore, vaccine efficacy can be greatly improved by combining VLPs from several types of HPV into one multivalent vaccine. ${ }^{18}$

Currently, a bivalent vaccine that protects against two high-risk HPV types, and a quadrivalent vaccine that protects against two high-risk and two low-risk HPV types are available. The two vaccines are: Cervarix ${ }^{\circledR}$ (bivalent vaccine) produced by GlaxoSmithKline (Brentford, UK) and Gardasil $^{\circledR}$ (quadrivalent vaccine) produced by Merck and Co, Inc (Whitehouse Station, NJ, USA). ${ }^{19}$ Both vaccines protect against HPV Types 16 and 18 while the Gardasil vaccine also protects against Condyloma acuminatae (genital warts) caused by HPV Types 6 and 11. To maximize effectiveness, the vaccine needs to be given to girls before they are sexually active ${ }^{20}$ as the vaccines have no protective effect among women who have already been infected with HPV 16 and 18 before vaccination. ${ }^{21}$

Knowledge of HPV and awareness of HPV vaccines by the general populace varies. ${ }^{9,22,23}$ Different regions of the world have reported different awareness levels regarding HPV and its potential to cause cancer in the general public. Studies in the USA documented high levels of awareness to HPV and its vaccine in the general populace. One study documented an awareness level of $71 \%$ in Latino women in New Jersey. ${ }^{24}$

According to a study in Brazil, 50\% of all their study subjects had some knowledge of HPV or cervical cancer. Some authors reported that having had a personal, familiar, or friendly history of previous sexually transmitted infections (STI) or cervical cancer were associated with an increased awareness of HPV and accurate knowledge of the HPVcervical cancer link. ${ }^{2,25,26}$ In a survey of British women aged 16-97 using an open question to elicit the causes of cervical cancer, only $2.5 \%$ mentioned HPV and $7 \%$ mentioned an unspecified sexually transmitted virus/infection. ${ }^{27}$

In a study in Malaysia, only $26 \%$ of the study population had ever heard about HPV or its vaccine and they noted that lack of awareness constituted an important barrier to the use of the vaccine in this country. ${ }^{28}$

Reports from various studies in Nigeria have shown that awareness of HPV infection and vaccines and the acceptability of these vaccines among the general public are very low even among health care providers. One study reported poor knowledge of the HPV vaccines among female nurses at Lagos University Teaching Hospital. ${ }^{9}$ This study noted that despite this poor knowledge, most of the nurses expressed a strong desire to be vaccinated and their intention to recommend the vaccine for preadolescent girls. The main reason given overall for not recommending the vaccines was lack of information. In another study in Abuja, they found a low level of awareness regarding HPV and cervical cancer among the urban and rural dwellers of Gwagwalada Area Council. ${ }^{10}$ Research has shown that knowledge of HPV is directly correlated to vaccine acceptance. ${ }^{9,29}$ Initial studies in the US, UK, and even Nigeria showed that HPV vaccine acceptance among parents was high prior to availability of the vaccine, even though HPV awareness was fairly low. ${ }^{10,30}$ The UK based studies report that people generally know little about HPV, but after the provision of information, most supported the introduction of the vaccine. ${ }^{2,31}$ Relatively 
few investigations have addressed the parent's support and willingness for HPV vaccination of school age children in Nigeria. The majority of the research that has been undertaken has been based in Western countries ${ }^{19,32}$ and they report varied parental (especially maternal) and adolescent attitudes towards HPV vaccination. Among parents studied in a Swedish population-based survey, $76 \%$ were willing to vaccinate their child if the vaccine is free and $63 \%$ were willing to vaccinate even if the vaccine comes with a cost. ${ }^{3}$ The relatively small number of Nigerian based studies undertaken to date also tend to report similar findings of low knowledge but high acceptance.

The inclusion of a new vaccine in an immunization program will require consideration of some technical and social factors, such as the disease burden, vaccine efficacy, safety, immunogenicity, cost, and the immunization strategy. Equally important are public knowledge and acceptance of the vaccine. ${ }^{18}$ Although, HPV infection is common and its consequences can be severe, information about it among the majority of the population is low or nonexistent. Previous studies have also shown inadequate knowledge about HPV prevention methods among women. This is particularly true among people with lower socioeconomic status. ${ }^{33}$ Attitudinal and cultural aspects of HPV infection and cervical cancer can play an important role in infection rates, prevention methods including vaccine uptake, the cost, morbidity, and mortality associated with HPV-related diseases. People's perception of the risk of HPV infection and the benefits of vaccination will lead to greater acceptance of the vaccine policy. ${ }^{34}$

The aim of this study is to assess mothers' HPV knowledge and their willingness to vaccinate their adolescent daughters in Lagos, Nigeria. This study is timely as there is a dearth of literature that assessed mothers' views of HPV vaccination in Nigeria. Herein we present findings that would be useful to policy makers and program managers working in the area of immunization and reproductive health.

\section{Methods}

This study was a community-based, descriptive crosssectional study carried out in July, 2012 in Shomolu local government area (LGA) of Lagos State, Nigeria. Shomolu is one of 20 LGAs in Lagos State with a population of about 402,673 inhabitants of which 195,024 are females. ${ }^{35}$

A sample size of 290 was calculated using the formula for descriptive studies:

$$
\mathrm{n}=\mathrm{Z}^{2} \mathrm{Pq} / \mathrm{d}^{2}
$$

Where $\mathrm{n}=$ sample size $. \mathrm{Z}=\mathrm{z}$ statistics at a specific confidence level (eg, 95\%). $\mathrm{P}=$ prevalence or proportion of an attribute that is present in the population. $\mathrm{q}=\mathrm{I}-\mathrm{P} ; \mathrm{d}=$ desired level of precision (0.05), $\mathrm{P}=23.3 \%$ (proportion of people who have heard of HPV vaccine). ${ }^{9}$

Multistage sampling method was employed to select mothers of female adolescents (aged 10-19 years) who reside in Shomolu and were recruited. The selection of Shomolu LGA (including the streets and houses where the study was conducted) and the participants that were recruited, were all done by balloting.

Approval for this research was obtained from the Research and Ethics Committee of Lagos University Teaching Hospital. Permission for the research was also obtained from the Medical Officer of Health (MOH) of Shomolu LGA. Informed consent was obtained from the women prior to the administration of questionnaire.

A structured, pretested, interviewer-administered questionnaire was used for data collection. The questionnaire had four sections: socio-demography; knowledge/awareness of HPV and HPV vaccines; acceptance/practice of immunizations and HPV vaccinations; and barriers to HPV immunizations.

Data collected were entered into and analyzed using Epi Info ${ }^{\mathrm{TM}}$ version 7 statistical package (designed by Centers for Disease Control and Preventation [CDC]). Comparison of categorical responses was evaluated using chi-square test or Fisher's exact test. Statistical significance was set at 0.05 .

\section{Results}

The ages of the respondents ranged from 24-62 years with a mean age of $40.1 \pm 6.9$ years. All respondents had between 1 and 6 adolescent daughters with a mean of $2.0 \pm 1.0$ adolescent daughters. Table 1 shows the socio-demographic characteristics of the study participants.

The awareness and knowledge of HPV among the participants were low. The distribution of respondents who answered correctly to each of the different questions on the knowledge about HPV and cervical cancer showed that less than one-third $(27.9 \%)$ of the respondents had ever heard of HPV while only $19.7 \%$ had heard of HPV vaccines.

In contrast, the majority of respondents had heard of cervical cancer though only $34.5 \%$ knew that HPV is a risk factor for cervical cancer. Among those who had heard of HPV, 74\% knew the route of transmission for HPV and the main aim of HPV vaccination while 39 (48.1\%) knew the recommended age for HPV vaccination in Nigeria (Table 2).

Among the 81 participants who had heard of HPV, 26 $(32 \%)$ reported the media as the source of their knowledge 
Table I Socio-demographic characteristics of the study participants

\begin{tabular}{lll}
\hline Ethnicity & Frequency (n) & Percentage \\
\hline Hausa & 30 & 10.4 \\
lgbo & 80 & 27.7 \\
Yoruba & 112 & 38.4 \\
Other & 68 & 23.5 \\
Total & 290 & 100 \\
Education & & \\
$\quad$ None & 13 & 4.5 \\
Primary & 38 & 13.1 \\
Secondary & 137 & 47.2 \\
Tertiary & 102 & 35.2 \\
$\quad$ Total & 290 & 100 \\
Occupation & & \\
Professionals & 99 & 34.1 \\
Skilled & 151 & 52.1 \\
Unskilled & 2 & 0.7 \\
Unemployed & 32 & 11.0 \\
$\quad$ Total & 290 & 100 \\
Religion & & \\
Christian & 228 & 78.6 \\
Islam & 61 & 21.0 \\
Others & 1 & 0.3 \\
Total & 290 & 100 \\
\hline Not & &
\end{tabular}

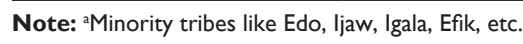

while $24(29 \%)$ reported health workers as their source of knowledge. Only 2 (2.5\%) participants mentioned school or other formal settings as their source of information on HPV.

Routine immunization coverage was generally high among the participants. Most of the respondents accept and offer routine immunization to their children (98.3\%), mainly because it was compulsory (97.6\%). Only 20 (6.9\%) of the respondents had immunized their daughters against HPV. Two hundred and forty eight (88.9\%) stated that they would want

Table 2 Knowledge of HPV and cervical cancer

\begin{tabular}{lll}
\hline Question & Yes $(\mathbf{n}=\mathbf{2 9 0})$ & Percentage \\
\hline Ever heard of HPV & 81 & 27.9 \\
Ever heard of HPV vaccines & 57 & 19.7 \\
Aware that HPV can cause cancer & 76 & 26.9 \\
Ever heard of cervical cancer & 230 & 79.6 \\
& $\begin{array}{l}\text { Correct answer } \\
(\mathbf{n}=\mathbf{8 1})\end{array}$ \\
\cline { 2 - 2 } & 78 & 96.3 \\
HPV is a risk factor for cervical & & \\
cancer & 60 & 74.1 \\
HPV is sexually transmitted & 66 & 81.5 \\
HPV vaccination prevents cervical & & \\
cancer & & 34.6 \\
HPV immunization pre-sexual debut & 28 & 48.1 \\
HPV vaccination recommended in & 39 & \\
I0-19 years old & &
\end{tabular}

Abbreviation: HPV, human papilloma virus. their daughters to be vaccinated. Nearly all the respondents $(91 \%)$ would recommend the vaccines to friends or relatives. Most of the participants (96.5\%) indicated that they want more information on HPV and HPV vaccines. Ninety five percent of them also want their daughters to learn more about HPV and its prevention. For the few who would not want their daughters' vaccinated, inadequate information about HPV vaccines was the main reason for not being willing to vaccinate them.

HPV awareness increased with increasing level of education. All respondents with primary or no formal education had no knowledge of the vaccines whereas nearly half of those with tertiary education (44.1\%) had heard of the HPV vaccines; this was statistically significant, $(P<0.001$; Table 3$)$. Religion had no statistically significant influence on the awareness of HPV. Of the 81 respondents who were aware of HPV, 16 were Muslims. Of these 16 Muslims, four had vaccinated their daughters with HPV vaccines. Ethnicity also showed no statistically significant influence on HPV awareness.

Of the 290 respondents, 88 (30.3\%) had no worry or concerns regarding vaccinating their daughters against HPV. However, the remaining 202 participants had at least one concern that may prevent them vaccinating their daughters with HPV vaccines (Table 4). The majority of the mothers $(51.5 \%)$ who showed concern did not know where to access the vaccines while $46(22.8 \%)$ of the mothers were worried about the vaccine cost. Only $6.4 \%$ of the mothers were concerned that the vaccines may expose the girls to risky sexual behaviors.

\section{Discussion}

The majority of the respondents had no awareness of HPV or HPV vaccines; only $81(27.9 \%)$ had heard of HPV. This finding is in accordance with previous studies round the globe (Nigeria inclusive) which have demonstrated that people generally know little regarding HPV. ${ }^{2,9}$

Table 3 Association between education and awareness of HPV vaccines

\begin{tabular}{llll}
\hline Education & \multicolumn{2}{l}{ Awareness of HPV vaccines } & Total \\
\cline { 2 - 3 } & Yes (\%) & No (\%) & \\
\hline No formal & $0(0.00)$ & $13(100)$ & $13(100)$ \\
Primary & $0(0.00)$ & $38(100)$ & $38(100)$ \\
Secondary & $12(8.9)$ & $125(91.2)$ & $137(100)$ \\
Tertiary & $45(44.1)$ & $57(55.9)$ & $102(100)$ \\
Total & $57(19.7)$ & $233(80.3)$ & $290(100)$ \\
\hline
\end{tabular}

Notes: $\chi^{2}=61.07, \mathrm{df}=3, P$-value $<0.001$.

Abbreviations: $\mathrm{df}$, degrees of freedom; $\mathrm{HPV}$, human papilloma virus. 
Table 4 Possible barriers to HPV immunization among mothers with concerns regarding HPV vaccines

\begin{tabular}{ll}
\hline Barrier to vaccination & Frequency (\%) \\
& $\mathbf{N}=\mathbf{2 0 2}$ \\
\hline The vaccine is too costly & $46(22.8)$ \\
The vaccine is not safe & $5(2.5)$ \\
Does not trust the efficacy of the vaccines & $8(4)$ \\
May expose adolescents to risky sexual behaviors & $13(6.4)$ \\
Does not know where or how to access the vaccines & $104(51.5)$ \\
Does not have sufficient information about HPV yet & $24(11.8)$ \\
Afraid to give them multiple injections & $2(1)$ \\
Total & $202(100)$ \\
\hline
\end{tabular}

Abbreviation: HPV, human papilloma virus.

Despite the low awareness of HPV in the present study, most of the participants were willing and supportive of HPV vaccination of adolescent girls. This agrees with similar findings in Honduras in which few mothers were aware of HPV or HPV vaccination (13\%), but their acceptance of HPV vaccination for their daughters was very high. ${ }^{22}$

Although the awareness of HPV and its vaccine was very low, the majority of the respondents (79.6\%) were aware of cervical cancer. Most of those aware of cervical cancer were, however, not aware of the relationship between HPV and cervical cancer and only a few (21\%) knew that HPV is transmitted sexually. The relatively high knowledge of cervical cancer is consistent with similar findings by another author in Nigeria that reported high awareness of cervical cancer (close to 99\%) in their study. ${ }^{9}$ These findings suggest that awareness creation concerning cervical cancer is effective. However, because the HPV vaccine is a relatively new development, the majority of the populace have yet to learn about it. In Nigeria, the HPV vaccine was just launched and inaugurated by the federal government in 2011 and only six pilot centers were currently commissioned to give HPV vaccines, apart from those offered by private facilities. The low awareness for HPV vaccine in this study shows that much work is needed to create awareness for HPV vaccines in Nigeria. This can be achieved with the development of health promotion and educational strategies for the public. Considering the high burden of cervical cancer in Nigeria, creation of HPV awareness and promotion of HPV vaccination will be a step in the right direction.

The high level of willingness to give HPV vaccinations shown by the respondents is consistent with what has been reported in other recent studies in Italy and Honduras ${ }^{2,4,9,22}$ which reported the willingness of the majority $(>70 \%)$ of respondents to recommend the vaccine to others or to accept it for themselves. As nearly all participants offer routine immunization to their children, immunization clinics can be a very good avenue to inform mothers of HPV vaccines and schedule their daughters for the vaccination.

Exploration of the factors influencing awareness and attitudes toward HPV in the present study indicates that women with higher educational qualifications had a higher awareness of HPV vaccines than those who were less educated. This finding may stem from the fact that the educated mothers were more exposed to information on HPV, such as from the media, internet, books, journals, seminars, etc, unlike uneducated women whose sole source of information on health matters may be relatives and occasionally health workers. A study performed in Israel has shown that the more aware an individual is about the dangers inherent in contracting HPV, the higher the interest shown in preventive methods. ${ }^{23}$

Our study showed that majority of our respondents obtained their knowledge of HPV from the media. A similar study in Abuja reported health officials as the major source of information on HPV. ${ }^{10}$ Their study, however, did not document the media as a source of information on HPV. Another study in Owerri reported the media, specifically the internet, as a prominent source of reproductive health information in adolescent girls. ${ }^{36}$ The use of the media as an avenue for quality health promotion on HPV vaccines will greatly increase the probability of creating optimal awareness of the vaccines in the population within a shorter time, thereby increasing its uptake. This will also reduce the burden on the limited health workers available.

Apart from education, other socio-demographic variables (ethnicity and religion) did not seem to exert much influence on awareness or knowledge of the practice of HPV vaccination. This is in contrast to the findings from a study conducted in Israel in which religion and religiosity exerted the greatest influence on the mothers' intention to vaccinate their daughters, with religious Muslim women having the lowest intention to vaccinate their daughters against HPV. ${ }^{23}$ The explanation for religion not having much effect in the present study may be because the study population was majority Christians (78.6\%) and the study was performed in the Southern part of Nigeria. Christians in Nigeria and the South have not shown any known negative attitude towards any of the vaccines offered in Nigeria. ${ }^{34}$

The present study highlighted some concerns shown by the study participants, which, if not well managed and dealt with, may constitute barriers to successful HPV vaccination in Nigeria. Majority of the participants (51.5\%) highlighted lack of knowledge and access to the HPV vaccines as a major obstacle to HPV immunization. It has been 
documented in a study in Malaysia that lack of awareness constituted an important barrier to the uptake of the vaccine in that country. ${ }^{28}$ If an individual is not aware that a vaccine can prevent a certain disease, the likelihood of immunizing against that disease is low.

The HPV vaccine is advocated for adolescents and young adults; however, the immunization schedule in Nigeria has not made provisions for routine immunization of adolescents against any disease (except the tetanus vaccine for child bearing women 15 years and older) unlike in Western countries where adolescents routinely receive certain immunizations. ${ }^{37}$ It is possible to incorporate HPV vaccination of adolescents into the routine immunization schedule in use in Nigeria. For example, in the USA, Tdap, sometimes known as dTap, (an acronym for the collective vaccines preventing tetanus, diphtheria, and pertussis) is a recommended vaccine for adolescents and forms part of their immunization schedule. ${ }^{37}$ During this visit, HPV vaccines may also be given to these adolescents. This policy can be emulated in Nigeria. Government and stakeholders, especially those in primary care, should use every means and opportunity to deliver this very important vaccine to the at risk population and consistently rectify any misconceptions and confusions about HPV vaccines in order that Nigerians may benefit maximally from the HPV vaccine, thereby reducing the incidence of cervical cancer in Nigeria.

\section{Conclusion}

This research showed that the knowledge of HPV and HPV vaccines in Nigeria is low. Less than one-third (27.93\%) of respondents have ever heard of HPV while only $19.7 \%$ have heard of HPV vaccines. Despite low knowledge of HPV and HPV vaccines, mothers were willing to vaccinate their daughters. They were also willing to recommend the vaccines to others $(91.0 \%)$. We recommend improving mothers' knowledge through education and the possible inclusion of the vaccine in our national immunization schedule to eliminate the financial barrier.

\section{Disclosure}

The authors report no conflicts of interest in this work.

\section{References}

1. Richardson H, Kelsall G, Tellier P, et al. The natural history of typespecific HPV infections in female university students. Cancer Epidemiol Biomarkers Prev. 2003;12(6):485-490.

2. Di Giuseppe G, Abbate R, Liguori G, Albano L, Angelillo IF. Human papillomavirus and vaccination: knowledge, attitudes, and behavioural intention in adolescents and young women in Italy. Br J Cancer. 2008;99(2):225-229.
3. Dahlstrom LA, Tran TN, Lundholm C, Young C, Sundström K, Sparén P. Attitudes to HPV vaccination among parents of children aged 12-15 years-a population-based survey in Sweden. Int J Cancer. 2010;126(2):500-507.

4. Trim K, Nagji N, Elit L, Roy K. Parental knowledge, attitudes, and behaviors towards human papillomavirus vaccination for their children: a systematic review from 2001 to 2011. Obstet Gynecol Int. 2012;2012: 921236.

5. Anorlu RI. Cervical cancer: the sub-Saharan African perspective. Reprod Health Matters. 2008;16(32):41-49.

6. Burk RD, Kelly P, Feldman J, et al. Declining prevalence of cervicovaginal human papillomavirus infection with age is independent of other risk factors. Sex Transm Dis. 1996;23(4):333-341.

7. World Health Organization. Information Centre on HPV and Cervical Cancer. Human Papillomavirus and Related Cancers in Nigeria. Summary Report 2010. Accessed June 2, 2012.

8. Rama CH, Villa LL, Pagliusi S, et al. Awareness and knowledge of $\mathrm{HPV}$, cervical cancer, and vaccines in young women after first delivery in Sao Paulo Brazil - a cross-sectional study. BMC Womens Health. 2010;10:35-41.

9. Makwe CC, Anorlu RI. Knowledge of and attitude toward human papillomavirus infection and vaccines among female nurses at a tertiary hospital in Nigeria. Int J Womens Health. 2011;3:313-317.

10. Nnodu O, Erinosho L, Jamda M, Olaniyi O, Adelaiye R, Lawson L, et al. Knowledge and Attitudes towards cervical cancer and human papillomavirus: a Nigerian pilot study. Afr J Reprod Health. 2010;14(1):95-108.

11. Insinga RP, Glass AG, Rush BB. The health care costs of cervical human papillomavirus - related disease. Am J Obst Gynecol. 2004;191(1):114-120.

12. Zhou J, Sun XY, Stenzel DJ, Frazer IH. Expression of vaccinia recombinant HPV 16 L1 and L2 ORF proteins in epithelial cells is sufficient for assembly of HPV virion-like particles. Virology. 1991;185(1):251-257.

13. Hagensee ME, Yaegashi N, Galloway DA. Self-assembly of human papillomavirus type 1 capsids by expression of the L1 protein alone or by coexpression of the L1 and L2 capsid proteins. Virology. 1993;67(1):315-322.

14. Schiller JT, Davies P. Delivering on the promise: HPV vaccines and cervical cancer. Nat Rev Microbiol. 2004;2(4):343-347.

15. Suzich JA, Ghim SJ, Palmer-Hill FJ, et al. Systemic immunization with papillomavirus L1 protein completely prevents the development of viral mucosal papillomas. Proc Natl Acad Sci U S A. 1995;92(25): 11553-11557.

16. Jansen KU, Rosolowsky M, Schultz LD, et al. Vaccination with yeastexpressed cottontail rabbit papillomavirus (CRPV) virus-like particles protects rabbits from CRPV-induced papilloma formation. Vaccine. 1995;13(16):1509-1514.

17. Pastrana DV, Vass WC, Lowy DR, Schiller JT. NHPV16 VLP vaccine induces human antibodies that neutralize divergent variants of HPV16. Virology. 2001;279(1):361-369.

18. Soper D. Reducing the health burden of HPV infection through vaccination. Infect Dis Obstet Gynecol. 2006;2006 Suppl:83084.

19. Castellsagué X, Klaustermeier J, Carrilho C. Vaccine-related HPV genotypes in women with and without cervical cancer in Mozambique: burden and potential for prevention. Int J Cancer. 2008;122(8): 1901-1904.

20. Tialma WA, van Damme P. Who should be vaccinated against human papillomavirus? Int J Cynecol Cancer. 2006;16(4):1498-1499.

21. Markowitz LE, Dunne EF, Saraiya M, Lawson HW, Chesson H, Unger ER; Centers for Disease Control and Prevention (CDC); Advisory Committee on Immunization Practices (ACIP). Quadrivalent human papillomavirus vaccine: recommendations of the advisory committee on immunization practices (ACIP). MMWR Recomm Rep. 2007;56(RR-2): $1-24$.

22. Perkins RB, Langrish SM, Cotton DJ, Simon CJ. Maternal support for human papillomavirus vaccination in Honduras. $J$ Womens Health (Larchmt). 2011;20(1):85-90. 
23. Ben Natan M, Aharon O, Pclickshvili S, Gurman V. Attitude of Israeli mothers with vaccination of their daughters against human papilloma virus. J Pediatr Nurs. 2011;26(1):70-77.

24. Nøhr B, Munk C, Tryggvadottir L, et al. Awareness of human papillomavirus in a cohort of nearly 70,000 women from four Nordic countries. Acta Obstet Gynecol Scand. 2008;87(10):1048-1054.

25. Tiro JA, Meissner HI, Kobrin S, Chollette V. What do women in the US know about human papillomavirus and cervical cancer? Cancer Epidemiol Biomarkers Prev. 2007;16(2):288-294.

26. Marlow LA, Waller J, Wardle J. Public awareness that HPV is a risk factor for cervical cancer. Br J Cancer. 2007;97(5):691-694.

27. Al-Dubai SA, Alshagga MA, Al-Naggar RA, et al. Knowledge, attitudes and barriers for human papilloma virus (HPV) vaccines among Malaysian women. Asian Pac J Cancer Prev. 2010;11(4):887-892.

28. Dell DL, Chen H, Ahmad F, Stewart DE. Knowledge about human papillomavirus among adolescents. Obstet Gynecol. 2000;96(5 Pt 1): 653-656.

29. Poland GA, Jacobson RM, Koutsky LA, et al. Immunogenicity and reactogenicity of a novel vaccine for human papillomavirus 16: a 2-year randomized controlled clinical trial. Mayo Clin Proc. 2005;80(5):601-610.

30. Dinh TA, Rosenthal SL, Doan ED, et al. Attitudes of mothers in Da Nang, Vietnam toward a human papillomavirus vaccine. J Adolesc Health. 2007;40(6):559-563.

31. Oguntola S. Vaccination: easy way out of cervical cancer. The Nigerian Tribune. 14 October 2011. Available from: http://www.tribune.com.ng/ index.php/your-health/29655. Accessed June 20, 2012.
32. Woodhall SC, Lehtinen M, Verho T, Huhtala H, Hokkanen M, Kosunen E. Anticipated acceptance of HPV vaccination at the baseline of implementation: a survey of parental and adolescent knowledge and attitudes in Finland. J Adolesc Health. 2007;40(5):466-469.

33. Balogun MR, Odukoya OO, Oyediran MA, Ujomu PI. Cervical cancer awareness and preventive practices: a challenge for female urban slum dwellers in Lagos, Nigeria. Afr J Reprod Health. 2012;16(1): 75-82.

34. Sherris J, Friedman A, Wittet S, Philip D, Steben M, Saraiya M. Chapter 25: education, training, and communication for HPV vaccines. Vaccine. 2006;24 Suppl 3:S3/210-S3/218.

35. Federal Republic of Nigeria Official Gazette No 24, Vol 94, B 175-198. Legal notice on publication of Details of the breakdown of the National and State Provincial Totals of 2006 Census. Lagos, Nigeria. May 15, 2007.

36. Nwagwu WE. The Internet as a source of reproductive health information among adolescent girls in an urban city in Nigeria. $B M C$ Public Health. 2007;7:354.

37. Centers for Disease Control and Prevention (CDC). Updated recommendations for use of tetanus toxoid, reduced diphtheria toxoid and acellular pertussis (Tdap) vaccine from the Advisory Committee on Immunization Practices, 2010. MMWR Morb Mortal Wkly Rep. 2011;60(1):13-15.
International Journal of Women's Health

\section{Publish your work in this journal}

The International Journal of Women's Health is an international, peerreviewed open-access journal publishing original research, reports, editorials, reviews and commentaries on all aspects of women's healthcare including gynecology, obstetrics, and breast cancer. The manuscript management system is completely online and includes

\section{Dovepress}

a very quick and fair peer-review system, which is all easy to use. Visit http://www.dovepress.com/testimonials.php to read real quotes from published authors. 